\title{
Experimental verification of design calculations of the internal combustion engine cooling system
}

The article presents a comparative analysis of calculation results and measurement results of cooling module built on the basis of design calculations. The computations were made in software dedicated to the calculations of heat exchangers. The measurements were performed on a cooling system mounted in a special purpose vehicle together with a combustion engine, which was loaded by an engine dynamometer. Based on the comparison between input data for calculations and results of measurements, differences were found, therefore changes were proposed to be made in the model.

Key words: cooling system, combustion engine, designing, numerical calculation

\section{Introduction}

Cooling systems of modern engines are becoming increasingly complex. This results from the high technical development of combustion engines associated with the need for thermal stabilization of many elements of both the engine and its instrumentation $[1,2]$. Hence, the design of cooling systems requires knowledge of not only the principles of heat exchange, but also the construction of modern engines and the elements that require thermal stabilization. The arrangement of the elements of the cooling system and the impact of systems surrounding it is also important. Computer software with various degrees of complexity are the tool that supports the engineer in the designing process; they enable the construction of complex systems and perform highly advanced calculations. However, it is not always possible to take into account all the factors affecting the system and all the phe- nomena taking place in it. Therefore, the ability to verify the calculation results in an experimental way is desirable. The work presents a computational model of engine cooling system, results of calculations and measurements performed on a system built using the calculation results. It also provides a comparison of the obtained values.

\section{Computational model of the cooling system}

The cooling system is to be applied to the engine of a special purpose vehicle. The vehicle's layout conditions require horizontal placement of heat exchangers above the powerpack. The cooling system is designed to cool the engine coolant, engine charge air, gearbox oil, hydraulic oil of fan drive and hydraulic system. In addition, the cooling system must contain a condenser for the air conditioning system of the passenger space.

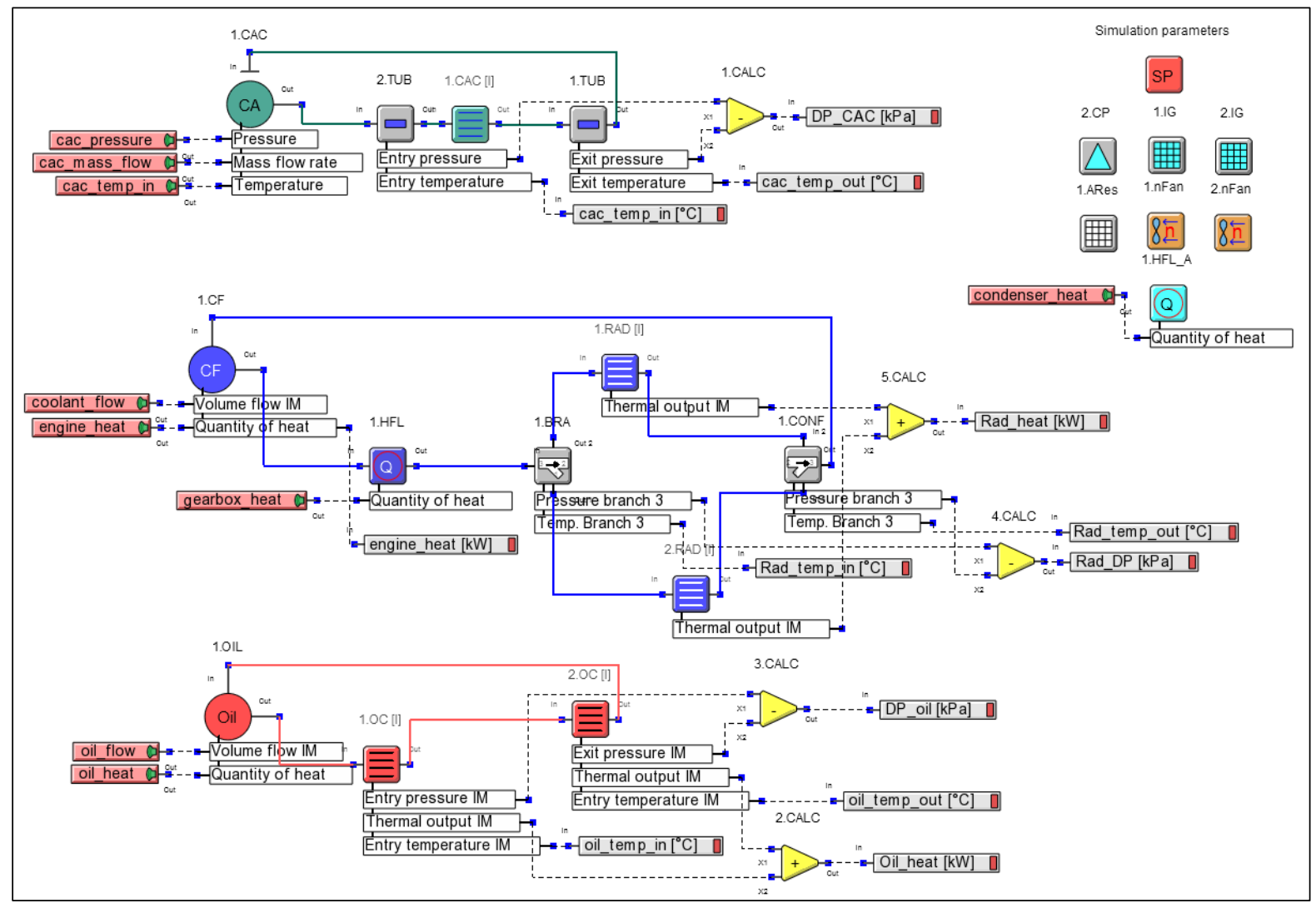

Fig. 1. 1D model of the cooling system 
The calculations were performed in the KULI software, using BSPL core systems. The 1D model of the cooling system is shown in Fig. 1. The coolant circuit (blue circuit) contains heat from the engine, heat absorbed by the coolant from the oil in the gearbox exchanger and two heat exchangers in the parallel system. The heat exchanger models were built on the basis of measurements made on a heat exchanger with specific dimensions and core system. They were then scaled in the software by changing the height and length of the heat exchanger core. For a given system, the measurements were made for an insufficiently thick core. Therefore, the required thickness was simulated by parallel placement of two heat exchangers of the same size. In the cooling circuit of the charge air (green circuit), flow losses are a very important aspect, so the tube sections between the engine and the heat exchanger were taken into account. The oil cooler (red circuit) was modelled as a U-flow heat exchanger to achieve better heat exchange results.

The 3D model of the cooling system, with a preset airflow path, is shown in Fig. 2. It shows the arrangement of the heat exchangers in the module. It is assumed that a cover in the form of blinds is to be installed in front of the heat exchangers. Due to the lack of information about the dimensions and parameters of the condenser, its influence on other elements of the cooling system was taken into account by ascribing a value of the heat absorbed from the condenser to the cooling air. This value was ascribed between the cover and the heat exchangers.

Axial fans are used to ensure forced airflow through the heat exchangers in engine cooling systems. However, the limited space for the installation of the cooling system and its special dimensions resulted in the selection of two mixed flow fans. For this reason, too, the space available for the exit air is limited to two areas with a small cross-section, on which the blinds were fitted.

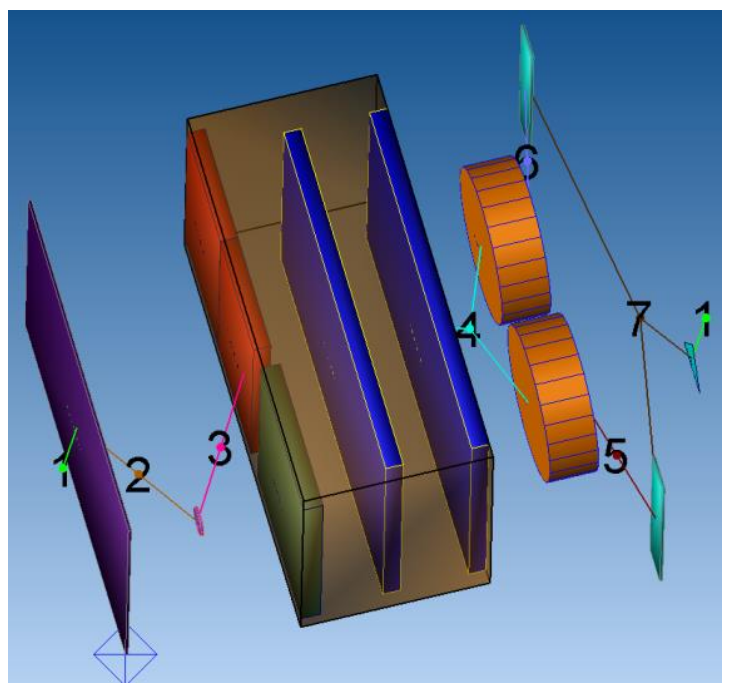

Fig. 2. 3D model of the cooling system (violet - inlet grit, green - charge air cooler, red - oil cooler, blue - radiator, orange - fan, light green outlet grit)

\section{Results of calculations}

The calculations were made for an ambient temperature of $50^{\circ} \mathrm{C}$ because the cooling system is to be designed for this value. The maximum temperature of the coolant at the exit of the engine can reach $105^{\circ} \mathrm{C}$, the gearbox exchanger is attached to the coolant flow system after the engine but before the thermostat. 1.1 safety factor is assumed for all heat exchangers. The cooling system cover is modelled as a blind with a clearance of $50 \%$. The air exit covers of the fans were initially modeled as blinds with a clearance of $50 \%$, but, due to the results obtained, calculations for $70 \%$ clearance blinds were also performed. The results of the calculations for both cases, with and without heat from the condenser, are shown in Table 1.

Table 1. Results of design calculations

\begin{tabular}{|c|c|c|c|c|c|}
\hline Value & Unit & Exit sh & rs $50 \%$ & Exit sh & rs $70 \%$ \\
\hline Ambient temperature & ${ }^{\circ} \mathrm{C}$ & 50 & 50 & 50 & 50 \\
\hline Condenser heat & $\mathrm{kW}$ & 22 & $\mathbf{0}$ & 22 & $\mathbf{0}$ \\
\hline Condenser air entry temp & ${ }^{\circ} \mathrm{C}$ & 50 & 50 & 50 & 50 \\
\hline Condenser air exit temp & ${ }^{\circ} \mathrm{C}$ & 54.4 & 50.0 & 53.1 & 50.0 \\
\hline CAC mass flow rate & $\mathrm{kg} / \mathrm{s}$ & 0.36 & 0.36 & 0.36 & 0.36 \\
\hline CAC entry temperature & ${ }^{\circ} \mathrm{C}$ & 212 & 212 & 212 & 212 \\
\hline CAC exit temperature & ${ }^{\circ} \mathrm{C}$ & 78.9 & 75.2 & 73.1 & 70.5 \\
\hline CAC pressure drop & $\mathrm{kPa}$ & 5.5 & 5.5 & 5.4 & 5.3 \\
\hline CAC+ pipe pressure drop & $\mathrm{kPa}$ & 6.1 & 6.1 & 6.0 & 6.0 \\
\hline Thermal output & $\mathrm{kW}$ & 50.2 & 51.6 & 52.4 & 53.4 \\
\hline Oil volume flow & $1 / \min$ & 70 & 70 & 70 & 70 \\
\hline Oil cooler entry temp & ${ }^{\circ} \mathrm{C}$ & 82.9 & 78.6 & 78.5 & 75.5 \\
\hline Oil cooler exit temp & ${ }^{\circ} \mathrm{C}$ & 73.3 & 68.9 & 68.9 & 65.8 \\
\hline Oil cooler pressure drop & $\mathrm{kPa}$ & 28.4 & 31.8 & 31.9 & 34.2 \\
\hline Oil heat rejection & $\mathrm{kW}$ & 20 & 20 & 20 & 20 \\
\hline Coolant volume flow & $1 / \min$ & 240.9 & 240.9 & 240.9 & 240.9 \\
\hline Engine exit temp & ${ }^{\circ} \mathrm{C}$ & 118.0 & 113.3 & 102.2 & 98.9 \\
\hline Transmission exit temp & ${ }^{\circ} \mathrm{C}$ & 122.7 & 118.0 & 106.9 & 103.6 \\
\hline Radiator entry temp & ${ }^{\circ} \mathrm{C}$ & 122.7 & 118.0 & 106.9 & 103.6 \\
\hline Radiator exit temp & ${ }^{\circ} \mathrm{C}$ & 110.9 & 106.2 & 95.1 & 91.9 \\
\hline Radiator pressure drop & $\mathrm{kPa}$ & 5.1 & 5.2 & 5.5 & 5.6 \\
\hline Transmission heat & $\mathrm{kW}$ & 70 & 70 & 70 & 70 \\
\hline Engine heat & $\mathrm{kW}$ & 105 & 105 & 105 & 105 \\
\hline Radiator heat rejection & $\mathrm{kW}$ & 175 & 175 & 175 & 175 \\
\hline Entry shutter clearance & $\%$ & 50 & 50 & 50 & 50 \\
\hline Entry shutter pressure drop & $\mathrm{Pa}$ & 31 & 32 & 63 & 64 \\
\hline Exit shutters clearance & $\%$ & 50 & 50 & 70 & 70 \\
\hline Exit shutters pressure drop & $\mathrm{Pa}$ & 3406 & 3450 & 3027 & 3055 \\
\hline Fan 1 - Input speed & $1 / \mathrm{min}$ & 3500 & 3500 & 3500 & 3500 \\
\hline Fan 1 - Air temperature & ${ }^{\circ} \mathrm{C}$ & 103.8 & 99.0 & 88.4 & 84.9 \\
\hline Fan 1 - Mass flow rate & $\mathrm{kg} / \mathrm{s}$ & 2.39 & 2.42 & 3.39 & 3.42 \\
\hline Fan 1 - Volume flow & $\mathrm{m}^{3} / \mathrm{s}$ & 2.61 & 2.61 & 3.55 & 3.55 \\
\hline Fan 1 - Pressure difference & $\mathrm{Pa}$ & 3641 & 3688 & 3462 & 3493 \\
\hline Fan 1 - Power & $\mathrm{kW}$ & 18.7 & 18.9 & 22.8 & 23.0 \\
\hline Fan 2 - Input speed & $1 / \mathrm{min}$ & 3500 & 3500 & 3500 & 3500 \\
\hline Fan 2 - Air temperature & ${ }^{\circ} \mathrm{C}$ & 103.8 & 99.0 & 88.2 & 85.1 \\
\hline Fan 2 - Mass flow rate & $\mathrm{kg} / \mathrm{s}$ & 2.39 & 2.42 & 3.38 & 3.41 \\
\hline Fan 2 - Volume flow & $\mathrm{m}^{3} / \mathrm{s}$ & 2.61 & 2.61 & 3.54 & 3.54 \\
\hline Fan 2 - Pressure difference & $\mathrm{Pa}$ & 3641 & 3688 & 3464 & 3496 \\
\hline Fan 2 - Power & $\mathrm{kW}$ & 18.7 & 18.9 & 22.8 & 23.0 \\
\hline
\end{tabular}

\section{Results of measurements}

The measurements were stationary, using a dynamometer connected to the shaft of the powerpack, in accordance with the procedures applied by the manufacturers of heavyduty engines during the acceptance of engines installed in vehicles. This means that the thermostat is to be fully open at all times during the measurements, the fans are to operate at the maximum presumed speed, and the engine is to be subjected to a constant load until the temperature of the coolant is stable. Measurements are made for maximum power and maximum torque. Figures 3, 4, 5, 6 and 7 show the measurement results for the maximum engine power. During the measurements, the passenger space air conditioning system was disabled, so the condenser did not emit heat to the cooling air. 


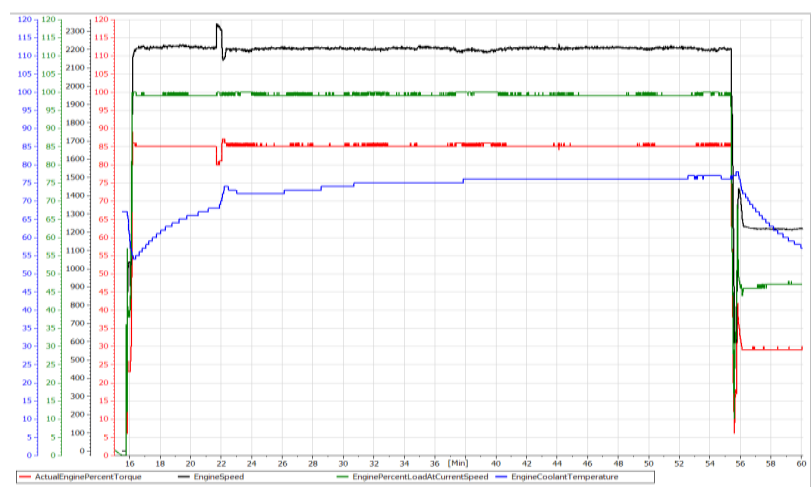

Fig. 3. Engine operating parameters during the measurement - engine speed (black), engine load (green), engine torque (red), coolant temperature (blue)

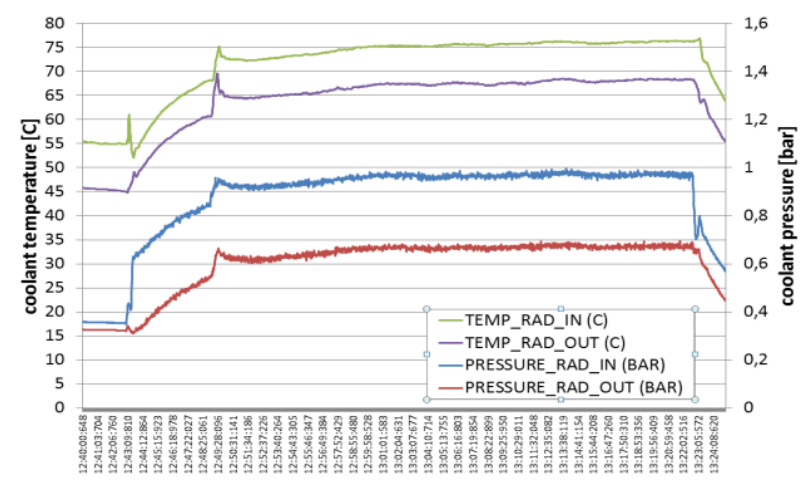

Fig. 4. Temperature and pressure of coolant measured before and after the liquid cooler

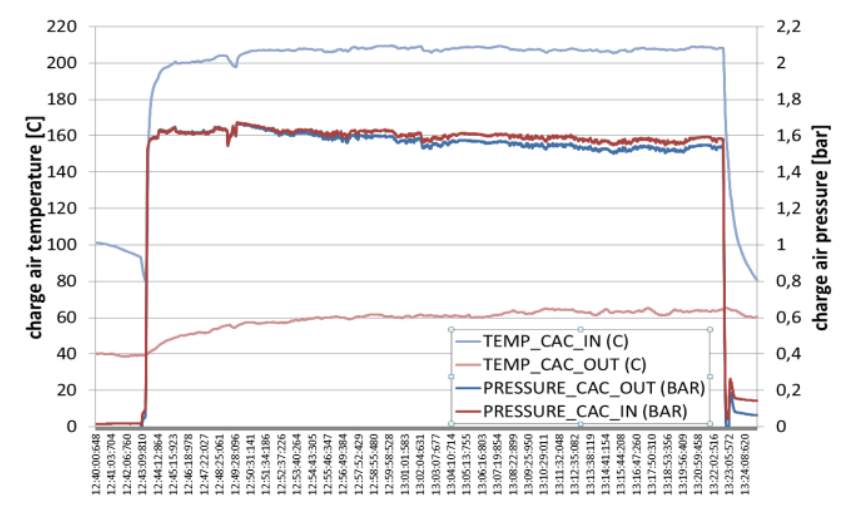

Fig. 5. Temperature and pressure of engine charge air measured before and after the air cooler



Fig. 6. Temperature and pressure of hydraulic oil measured before and after the oil cooler

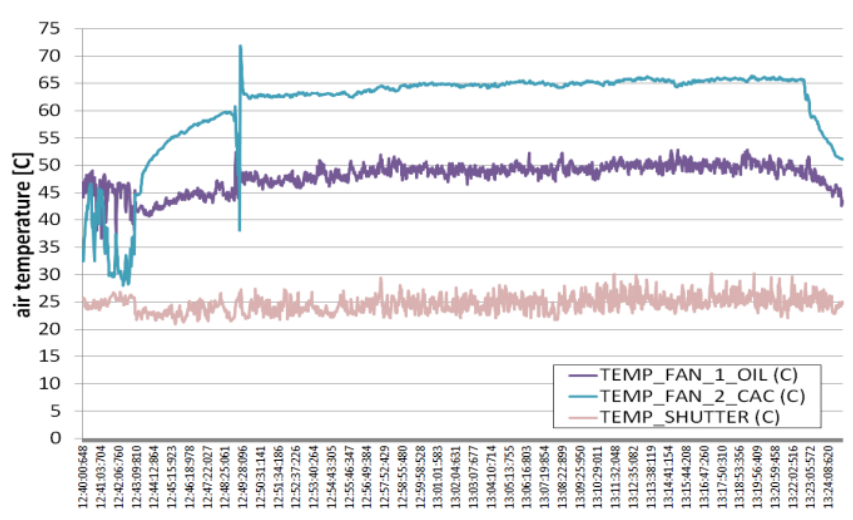

Fig. 7. Temperature of cooling air measured on the exchangers cover and on the fan cover

\section{Comparative analysis of calculation and measurement results}

The measurements were made at ambient temperature of $25^{\circ} \mathrm{C}$. Therefore, the calculations were also performed for this value. Stabilized values of measurement results and calculation values are presented in Table 2.

Table 2. Results of measurements and calculations for $25^{\circ} \mathrm{C}$ ambient temperature

\begin{tabular}{|l|c|c|c|c|}
\hline Parameter & Unit & $\begin{array}{c}\text { Test } \\
\text { results }\end{array}$ & Calculations & Calculations \\
\hline Ambient temperature & ${ }^{\circ} \mathrm{C}$ & 25.0 & 25.0 & 25.0 \\
\hline Radiator in & ${ }^{\circ} \mathrm{C}$ & 76.0 & 76.8 & 90.4 \\
\hline Radiator out & ${ }^{\circ} \mathrm{C}$ & 68.0 & 65.0 & 78.6 \\
\hline Radiator pressure drop & $\mathrm{kPa}$ & 30.0 & 5.7 & 5.7 \\
\hline Charge air cooler in & ${ }^{\circ} \mathrm{C}$ & 207.0 & 187.0 & 187.0 \\
\hline Charge air cooler out & ${ }^{\circ} \mathrm{C}$ & 63.0 & 44.5 & 49.2 \\
\hline CAC pressure drop & $\mathrm{kPa}$ & 4.5 & 4.8 & 5.0 \\
\hline Oil cooler in & ${ }^{\circ} \mathrm{C}$ & 55.0 & 51.5 & 54.4 \\
\hline Oil cooler out & ${ }^{\circ} \mathrm{C}$ & 35.0 & 41.5 & 44.4 \\
\hline Oil cooler pressure drop & $\mathrm{kPa}$ & 7.5 & 39.4 & 39.3 \\
\hline Fans speed & $\mathrm{rpm}$ & 3350 & 3500 & 3500 \\
\hline Air temperature out & ${ }^{\circ} \mathrm{C}$ & 57.5 & 57.5 & 70.4 \\
\hline Exit shutters clearance & $\%$ & no data & 70 & 50 \\
\hline
\end{tabular}

The cooling system uses two fans in parallel layout, what required their separation. This was achieved by creating spiral ducts for each of the fans. Due to the applied hydraulic system of fan drive, the maximum obtained rotational speed was by $150 \mathrm{rpm}$ lower than that assumed in the design calculations. The difference in oil temperature between the inlet and outlet of the oil cooler was twice as large as that obtained during the calculations.

The difference in temperature of the coolant between the inlet and outlet of the radiator during the measurements was $3.8 \mathrm{~K}$ lower than it resulted from the calculations. This may mean that the coolant flow was greater than that specified by the engine manufacturer to be used for calculations, as there was low flow resistance in the heat exchanger and tubes. At the same time, the heat dissipated from the gearbox to the coolant was actually lower than that provided for calculations. When the calculated heat and the temperature difference from the measurements are taken into account, the calculated volume flow rate of coolant is approximately $201 /$ min greater than that given for the engine without a cooling system.

The temperature of the charge air that passed the turbocharger was $20 \mathrm{~K}$ higher than specified in the engine cata- 
logue card, but, as the measurements showed, the temperature of the air before the air filter was also about $17 \mathrm{~K}$ higher than assumed by the manufacturer. Moreover, a condenser with a front surface larger than that of the air cooler was mounted on the air cooler. This increased the resistance of the airflow through this element of the cooling system. As a consequence of the differences, the charge air temperature that passed the air cooler was about $14-18 \mathrm{~K}$ higher than calculated.

Table 3. Results of adjusted calculations

\begin{tabular}{|c|c|c|c|}
\hline Value & Unit & \multicolumn{2}{|c|}{ Exit shutters $70 \%$} \\
\hline Ambient temperature & ${ }^{\circ} \mathrm{C}$ & 25 & 25 \\
\hline Condenser heat & $\mathrm{kW}$ & $\mathbf{0}$ & $\mathbf{0}$ \\
\hline Condenser pressure drop & $\mathrm{Pa}$ & 238 & 226 \\
\hline CAC fouling factor & $\%$ & 10 & 50 \\
\hline CAC mass flow rate & $\mathrm{kg} / \mathrm{s}$ & 0.36 & 0.36 \\
\hline CAC entry temperature & ${ }^{\circ} \mathrm{C}$ & 207 & 207 \\
\hline CAC exit temperature & ${ }^{\circ} \mathrm{C}$ & 52.2 & 56.3 \\
\hline CAC pressure drop & $\mathrm{kPa}$ & 5.1 & 5.2 \\
\hline CAC + pipe pressure drop & $\mathrm{kPa}$ & 5.7 & 5.8 \\
\hline Thermal output & $\mathrm{kW}$ & 57.1 & 55.6 \\
\hline Oil volume flow & $1 / \mathrm{min}$ & 31.8 & 31.8 \\
\hline Oil cooler entry temp & ${ }^{\circ} \mathrm{C}$ & 55.2 & 55.1 \\
\hline Oil cooler exit temp & ${ }^{\circ} \mathrm{C}$ & 35.3 & 35.2 \\
\hline Oil cooler pressure drop & $\mathrm{kPa}$ & 8.1 & 8.1 \\
\hline Oil heat rejection & $\mathrm{kW}$ & 18 & 18 \\
\hline Coolant volume flow & $1 / \mathrm{min}$ & 300.5 & 300.5 \\
\hline Engine exit temp & ${ }^{\circ} \mathrm{C}$ & 73.1 & 73.2 \\
\hline Transmission exit temp & ${ }^{\circ} \mathrm{C}$ & 75.8 & 75.9 \\
\hline Radiator entry temp & ${ }^{\circ} \mathrm{C}$ & 75.8 & 75.9 \\
\hline Radiator exit temp & ${ }^{\circ} \mathrm{C}$ & 67.4 & 67.6 \\
\hline Radiator pressure drop & $\mathrm{kPa}$ & 11.3 & 11.3 \\
\hline Transmission heat & $\mathrm{kW}$ & 50 & 50 \\
\hline Engine heat & $\mathrm{kW}$ & 105 & 105 \\
\hline Radiator heat rejection & $\mathrm{kW}$ & 155 & 155 \\
\hline Entry shutter clearance & $\%$ & 50 & 50 \\
\hline Entry shutter pressure drop & $\mathrm{Pa}$ & 63 & 63 \\
\hline Exit shutters clearance & $\%$ & 70 & 70 \\
\hline Exit shutters pressure drop & $\mathrm{Pa}$ & 3013 & 3001 \\
\hline Fan 1 Input speed & $1 / \mathrm{min}$ & 3350 & 3350 \\
\hline Fan 1 Air temperature & ${ }^{\circ} \mathrm{C}$ & 56.9 & 56.8 \\
\hline Fan 1 Mass flow rate & $\mathrm{kg} / \mathrm{s}$ & 3.55 & 3.54 \\
\hline Fan 1 Volume flow & $\mathrm{m}^{3} / \mathrm{s}$ & 3.36 & 3.35 \\
\hline Fan 1 Pressure difference & $\mathrm{Pa}$ & 3538 & 3542 \\
\hline Fan 1 Power & $\mathrm{kW}$ & 22.1 & 22.1 \\
\hline Fan 2 Input speed & $1 / \mathrm{min}$ & 3350 & 3350 \\
\hline Fan 2 Air temperature & ${ }^{\circ} \mathrm{C}$ & 56.9 & 56.8 \\
\hline Fan 2 Mass flow rate & $\mathrm{kg} / \mathrm{s}$ & 3.55 & 3.54 \\
\hline Fan 2 Volume flow & $\mathrm{m}^{3} / \mathrm{s}$ & 3.36 & 3.35 \\
\hline Fan 2 Pressure difference & $\mathrm{Pa}$ & 3538 & 3542 \\
\hline Fan 2 Power & $\mathrm{kW}$ & 22.1 & 22.1 \\
\hline
\end{tabular}

\section{Bibliography}

[1] WORSZTYNOWICZ, B. The influence of fuel type on the cooling system heat exchanger parameters in heavy - duty engines. Scientific Conference on Automotive Vehicles and Combustion Engines (KONMOT 2016) IOP Conf. Series: Materials Science and Engineering. 2016, 148, 012080.
Another series of calculations was made (Table 3) after introducing changes in the model that would lead to the results obtained during the measurements. The load value of the hydraulic system was verified for the lower rotational speed of the fans, what resulted in the reduction of the amount of heat dissipated to the oil cooler. In connection with the temperature change of $20 \mathrm{~K}$ obtained in the oil cooler, it was necessary to reduce the oil flow more than twice. The safety factor was also abandoned. The analysis of the parameters of the coolant circuit led to a reduction in the amount of heat dissipated from the gearbox exchanger to the coolant and an increase in the coolant flow. The safety factor was changed to 1.15 . Since the condenser parameters were still unknown, a condenser-sized exchanger was added to the airflow before the air cooler, what increased the charge air temperature before the engine by $4 \mathrm{~K}$. In addition, the charge air temperature at the inlet of the air cooler was changed to the measured temperature, resulting in a further $4 \mathrm{~K}$ temperature change before the engine. However, the temperature of the charge air was still about $10 \mathrm{~K}$ lower than during the measurements. Application of the safety factor equal to 1.5 resulted in further change in the temperature of the charge air, but it was still insufficient.

\section{Conclusions}

At the design stage, data is very often incomplete, so a number of assumptions must be made. In addition, as there are different suppliers of complex system components, such as the powerpack, not all parameters can be accurately estimated. Therefore, the experimental verification of the complete system parameters is a very important stage. The measurements showed differences between the results of calculations and measurements, largely due to the initial assumptions. But the layout aspects also influenced the measurement results, especially in the case of the engine charging system. This, however, can be modified. A larger number of measured parameters would allow for more accurate verification of the calculation results, including the impact of heat exchanger scaling in the software. However, based on ATB (Air to Boil Temperature), it can be concluded that the results of the calculations allowed to design a cooling system, with a condenser in its layout, that meets the requirements of operating at an ambient temperature of $50^{\circ} \mathrm{C}$.

[2] WORSZTYNOWICZ, B. The influence of the drive type in city bus on the cooling system parameters. Scientific Conference on Automotive Vehicles and Combustion Engines (KONMOT 2018) IOP Conf. Series: Materials Science and Engineering. 2018, 421, 042084.

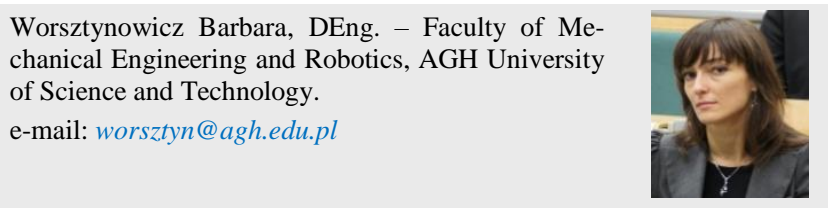

